\title{
Alfabetização científica: uma possibilidade para a inclusão social ${ }^{*}$
}

\author{
Attico Chassot \\ Universidade do Vale do Rio dos Sinos, Programa de Pós-Graduação em Educação
}

Há um continuado desafio: fazermos a migração do esoterismo ao exoterismo.

\section{A procura de um cenário: a escola}

Antes de apresentar o central deste texto - $a$ alfabetização científica -, parece oportuno, ainda que de uma maneira panorâmica, olhar a escola - na acepção de instituição que faz ensino formal, em qualquer nível de escolarização - nesses tempos de globalização. Não vou tecer, aqui e agora, comentários sobre os apossamentos da Organização Mundial do Comércio na fatia educação para dirigir sua voracidade por lucros, ${ }^{1}$ favorecendo a comercialização in-

* Sou muito grato aos árbitros anônimos da Revista Brasileira de Educação pelos circunstanciados pareceres e pelas valiosas sugestões. Procurei incorporar a maior parte delas a este texto. Evidentemente houve limitações de minha parte e o não atendimento de algumas das propostas deve ser atribuído a elas.

${ }^{1}$ Ver a Carta de Porto Alegre, "Llamamiento contra la transformación de la educación en mercancía”, produzida durante a ternacional dos serviços da educação como uma mercadoria qualquer. Parece não existir outro bem comerciável que segure um consumidor cativo por quatro ou mais anos, como o estudante que compra ensino de uma escola. Também, não preciso destacar as fantásticas modificações no mundo de hoje e o quanto elas atingem - e uso esse verbo na sua plenitude de significados - a educação, ou, mais especificamente, as salas de aula. Não temos dúvidas do quanto a globalização confere novas realidades à educação. Talvez, para uma facilitação, pudéssemos dirigir nosso olhar para duas direções. Primeira, o quanto são diferentes as múltiplas entradas do mundo exterior na sala de aula; e a outra direção, o quanto essa sala de aula se exterioriza, atualmente, de uma maneira diferenciada.

Sobre a primeira das situações não precisamos fazer muitas ilustrações. Comparem, por exemplo, o

III Cumbre Iberoamericana de Rectores de Universidades Públicas, 25 a 27 de abril de 2002. Publicado na Revista Brasileira de Educação n 21, set./dez. 2002, seção Documentos, p. 157-158. 
quanto eram enclausuradas as escolas de nossos avós às invasões externas, em relação às nossas salas de aula hoje, expostas às interferências do mundo externo. A escola, então, era referência na comunidade pelo conhecimento que detinha. Quanto à segunda, consideremos apenas a parcela de informações que nossos alunos e alunas trazem hoje à escola. Aqui temos que reconhecer que eles, não raro, superam as professoras e os professores nas possibilidades de acesso às fontes de informações. Há situações nas quais temos docentes desplugados ou sem televisão, que ensinam a alunos que surfam na internet ou estão conectados a redes de TV a cabo, perdendo a escola (e o professor) o papel de centro de referência do saber. A proletarização dos profissionais da educação os faz excluídos dos meios que transformam o planeta, onde a quantidade e a velocidade de informações o fazem parecer cada vez menor. Esse é o lado trágico em não poucas das contemplações da escola hoje (Chassot, 1998b).

Assim, parece que se pode afirmar que a globalização determinou, em tempos que nos são muito próximos, uma inversão no fluxo do conhecimento. Se antes o sentido era da escola para a comunidade, hoje é o mundo exterior que invade a escola. Assim, a escola pode não ter mudado; entretanto, pode-se afirmar que ela foi mudada. E talvez não diríamos isso há dez anos.

Não há, evidentemente, a necessidade (nem a possibilidade) de fazermos uma reconversão. Todavia, é permitido reivindicar para a escola um papel mais atuante na disseminação do conhecimento. Sonhadoramente, podemos pensar a escola sendo pólo de disseminação de informações privilegiadas.

\section{A ciência como um saber escolar}

Agora, posto esse preâmbulo, para não incorrer em generalizações indevidas restrinjamos as observações ao ensino de ciências. No século passado, nos anos de 1980, e talvez sem exagero se poderia dizer até o começo dos anos de 1990, víamos um ensino centrado quase exclusivamente na necessidade de fazer com que os estudantes adquirissem conhecimen- tos científicos. Não se escondia o quanto a transmissão (massiva) de conteúdos era o que importava. Um dos índices de eficiência de um professor - ou de um transmissor de conteúdos - era a quantidade de páginas repassadas aos estudantes - os receptores. Era preciso que os alunos se tornassem familiarizados (aqui, familiarizar poderia até significar simplesmente saber de cor) com as teorias, com os conceitos e com os processos científicos. Um estudante competente era aquele que sabia, isto é, que era depositário de conhecimentos. Talvez mais de um dos leitores deste texto poderá recordar quantos conhecimentos inúteis amealhou - especialmente quando foram feitas as primeiras iniciações na área das ciências - que há muito, afortunadamente, os deletou. Quantas classificações botânicas, quantas famílias zoológicas cujos nomes ainda perambulam em nossas memórias como cadáveres insepultos, quantas configurações eletrônicas de elementos químicos, quantas fórmulas de física sabidas por um tempo - até o dia de uma prova e depois desejadamente esquecidas.

Antes de mostrar salutares modificações nessa tendência, permito-me chamar a atenção para o sujeito da ação verbal antes descrita. Eram os professores (sujeitos) que faziam com que os estudantes (aqui vistos como passivos à ação do sujeito) adquirissem esses conhecimentos.

Quando se faz essas considerações, não há como não evocar, mais uma vez, as concepções de uma educação bancária, que Paulo Freire denunciava, com veemência, já em tempos anteriores aos referidos. Também a ele podemos creditar muitas das alterações nas tendências referidas.

Hoje não se pode mais conceber propostas para um ensino de ciências sem incluir nos currículos componentes que estejam orientados na busca de aspectos sociais e pessoais dos estudantes. Há ainda os que resistem a isso, especialmente quando se ascende aos diferentes níveis de ensino. Todavia, há uma adesão cada vez maior às novas perspectivas.

Muito provavelmente, um dos temas mais polêmicos quando se discute formação de professores de ciências é o quanto se precisa procurar uma ciência 
da escola (= o saber escolar; essa ciência da escola não é necessariamente uma produção exclusiva para a escola e/ou na escola, mas, como ensina Lopes (1999), envolve um processo de reelaboração de saberes de outros contextos sociais visando o atendimento das finalidades sociais da escolarização), que é significativamente diferente daquela ciência da universidade (= saber acadêmico). É usual defender até pela imensa dificuldade que existe de se fazer transposição (aqui transposição não é a palavra mais adequada, mas anuncia o que seria desejado) de conteúdos do ensino superior para os ensinos médio e fundamental - que o conhecimento científico é universal. Aqui universal parece ser, também, a estrutura verticalizada dos níveis de ensino.

\section{As necessidades de alfabetização científica}

A alfabetização científica pode ser considerada como uma das dimensões para potencializar alternativas que privilegiam uma educação mais comprometida. É recomendável enfatizar que essa deve ser uma preocupação muito significativa no ensino fundamental, mesmo que se advogue a necessidade de atenções quase idênticas também para o ensino médio. Sonhadoramente, ampliaria a proposta para incluir também, mesmo que isso possa causar arrepio em alguns, o ensino superior. Gostaria de ver essa inclusão privilegiada nas discussões que este texto possa desencadear.

Mesmo que adiante eu discuta o que é alfabetização científica, permito-me antecipar que defendo, como depois amplio, que a ciência seja uma linguagem; assim, ser alfabetizado cientificamente é saber ler a linguagem em que está escrita a natureza. É um analfabeto científico aquele incapaz de uma leitura do universo.

Atualmente, a alfabetização científica está colocada como uma linha emergente na didática das ciências, que comporta um conhecimento dos fazeres cotidianos da ciência, da linguagem científica e da decodificação das crenças aderidas a ela (Aguilar, 1999). Há aqueles que advogam que se deva procurar especialmente conhecimentos que estão no dia-a-dia do grande público, em particular os que são apresentados com imprecisão pelos meios de comunicação à opinião pública (Puigcerver \& Sans, 2002). Essas são propostas que vêem a alfabetização científica como uma possibilidade para fazer correções em ensinamentos distorcidos. Acredito que se possa pensar mais amplamente nas possibilidades de fazer com que alunos e alunas, ao entenderem a ciência, possam compreender melhor as manifestações do universo. Aqui se defende essa postura mais ampla, mesmo que se reconheça válida a outra tendência, de fazer correções em ensinamentos que são apresentados distorcidos.

Quando retomo e amplio os comentários acerca da alfabetização científica que estão em outro livro (Chassot, 2000), trago, mais uma vez, uma descrição de ciência que, mesmo que possa parecer reducionista, serve para os propósitos das discussões que se quer fazer aqui. A ciência pode ser considerada como uma linguagem construída pelos homens e pelas mulheres para explicar o nosso mundo natural. Compreendermos essa linguagem (da ciência) como entendemos algo escrito numa língua que conhecemos (por exemplo, quando se entende um texto escrito em português) é podermos compreender a linguagem na qual está (sendo) escrita a natureza. Também é verdade que nossas dificuldades diante de um texto em uma língua que não dominamos podem ser comparadas com as incompreensões para explicar muitos dos fenômenos que ocorrem na natureza. Por exemplo, é provável que alguns dos leitores deste texto não saibam distinguir se uma página de um livro ou de uma revista está escrito em sueco ou em norueguês, assim como deve haver nórdicos que talvez não reconheçam a diferença entre um texto em português e um em espanhol. Essa é a analogia que busco quando falo na ciência como uma linguagem.

Entender a ciência nos facilita, também, contribuir para controlar e prever as transformações que ocorrem na natureza. Assim, teremos condições de fazer com que essas transformações sejam propostas, para que conduzam a uma melhor qualidade de vida. Isto é, a intenção é colaborar para que essas transformações que envolvem o nosso cotidiano sejam 
conduzidas para que tenhamos melhores condições de vida. Isso é muito significativo. Aqueles que se dedicam à educação ambiental têm significativos estudos nessa área.

Dentre as muitas ciências, a química, por exemplo, é aquela que estuda como as substâncias se transformam e são transformadas em outras substâncias. Assim, ao definirmos os objetos de cada uma das ciências que conhecemos, como a física, a biologia, a geologia etc., nos damos conta das muitas interações e, particularmente, das intersecções entre esses objetos. Temos nesse conjunto as ciências naturais. Aqui ainda poderíamos incluir especializações de alguns campos muito específicos como a astrofísica, a geoquímica, a bioquímica. Se olharmos, por exemplo, as chamadas ciências humanas - a sociologia, a economia, a educação - e considerarmos as relações delas com as chamadas ciências naturais e a elas adicionarmos outros ramos das ciências, teremos a ciência, cada vez mais marcada por múltiplas interconexões.

Também se entende o quanto uma discussão, aparentemente simples, sobre se devemos dizer $a$ ciência ou as ciências, pode ser mais complexa do que imaginamos e se presta a muitas discussões epistemológicas, que não serão objeto deste texto. Granger (1994) tem um livro intitulado A ciência e as ciências. Acerca dessa discussão vale ler, entre outros, Chalmers (1994), Chrétien (1994) e Fourez (1995).

Aliás, é preciso dizer o quanto a divisão em ciências naturais e ciências humanas parece inadequada, pois a química, a física, a biologia e mesmo a matemática são também ciências humanas, porque são constructos estabelecidos pelos humanos. Lateralmente ainda, vale referir também o quanto a divisão em ciências hard e ciências soft é uma classificação no mínimo enviesada e, muito provavelmente, de autoria de um assim chamado cientista hard.

Ainda na busca de interconexões, em termos de disciplinas escolares vale considerar a atual proposta curricular, chamada pela divulgação oficial de "novo ensino médio". O currículo disciplinar é substituído pelo currículo em áreas. A organização do conhecimento escolar foi estabelecida em três áreas: lingua- gens, códigos e suas tecnologias (língua portuguesa, língua estrangeira moderna, educação física, artes e informática), ciências da natureza, matemática e suas tecnologias (biologia, física, química e matemática) e ciências humanas e suas tecnologias (história, geografia, filosofia, antropologia \& política e sociologia). Essa divisão - numa proposta oficial - tem como base reunir em uma mesma área aqueles conhecimentos que compartilham objetos de estudo e, portanto, que mais facilmente se comunicam (MEC \& SMTEC, 1999), criando condições para uma prática escolar de interdisciplinaridade, dentro de uma perspectiva interdisciplinar e contextualizada em oposição à fragmentação e descontextualização do ensino disciplinar.

É fácil entender o quanto as determinações oficiais buscam definir, por exemplo, o ensino de química como parte da área das ciências da natureza, matemática e suas tecnologias. Sou quase levado a inferir que há muitos envolvidos com esse ensino que não se dão conta de onde e como estão localizadas a física ou a química nas propostas curriculares. É verdade que o período de influência dessas últimas modificações é relativamente recente. Mas já há estudos, por exemplo, provenientes da comunidade envolvida com a educação química, que trazem questionamentos a esse quadro recente da educação brasileira.

Assim, Rozana Abreu, na sua dissertação de mestrado, analisando particularmente os Parâmetros Curriculares Nacionais para o Ensino Médio na área das ciências da natureza, matemática e suas tecnologias, mostra que a nova organização curricular proposta pelos documentos oficiais dos Parâmetros não favorece mudanças efetivas na promoção de um currículo mais integrado, na medida em que seus pressupostos estão associados às relações sociais da sociedade contemporânea, principalmente ao mercado de trabalho e ao mundo produtivo (Abreu, 2002).

Todavia, as diferentes concepções de Ciência nos convidam a adensar considerações acerca de uma proposta de vermos a ciência como uma linguagem. No segmento seguinte se ampliam discussões sobre alfabetização científica. Em outro texto (Chassot, 2003, no prelo) discuto como essa alfabetização científica 
ganha uma outra dimensão: o quanto com ela se pode fazer inclusão social.

\section{Ciência como linguagem}

Inicio aceitando críticas ao quanto a descrição da ciência como uma linguagem, que antes apresentei, possa ser considerada simplista. A seguir trago algumas preocupações. Também por isso reapresento criticamente outros textos que escrevi. Não ignoro que há (in)consistências teóricas nas minhas buscas. Vejome privilegiado em poder socializá-las aqui. Lateralmente, devo dizer que entendo que é para isso, também, que publicamos nossos textos em revistas.

Assim, considerar a ciência como "uma linguagem para facilitar nossa leitura do mundo natural" (Chassot, 1993, p. 37) e sabê-la como descrição do mundo natural ajuda a entendermos a nós mesmos e o ambiente que nos cerca.

Merece um comentário essa adjetivação de mundo que foi feita. A ciência não tem preocupações com a descrição, e muito menos com a explicação do mundo sobrenatural ou do mundo espiritual. $\mathrm{O}$ mundo natural é aqui usado na acepção de nosso mundo orgânico e inorgânico, que forma o que chamamos de natureza. Japiassu e Marcondes a definem como

\footnotetext{
um mundo visível ou físico (formado pelos reinos mineral, vegetal e animal) submetido às leis naturais, em oposição às idéias, sentimentos, emoções etc. governadas pelas leis morais e pelas leis políticas. $\left(1990\right.$, p. 177) ${ }^{2}$
}

Esses autores enfatizam que a natureza, num sentido teológico, deva ser considerada o mundo criado por Deus, em oposição à cultura no sentido daquilo que é criado pelas mulheres e pelos homens, assim, produto de uma obra humana.

Quando nos referimos ao entendimento do mun-

${ }^{2}$ A transcrição dessa definição não implica a aceitação da idéia de existência de três reinos na natureza, que há muito já está em desuso. do natural, há uma restrição epistemológica e ficamos limitados ao entendimento deste nosso mundo visível $^{3}$ onde estamos inseridos, logo, do qual somos parte. Com isso não estamos excluindo ou desqualificando as ciências humanas, que facilitam nosso entendimento social (e aqui incluo o político) ou emocional; elas podem estar incluídas no mundo dito natural. Estão excluídas, sim, as manifestações ditas sobrenaturais.

A elaboração dessa explicação do mundo natural - diria que isso é fazer ciência, como elaboração de um conjunto de conhecimentos metodicamente adquirido - é descrever a natureza numa linguagem dita científica. Propiciar o entendimento ou a leitura dessa linguagem é fazer alfabetização científica.

Há, todavia, uma outra dimensão em termos de exigências: propiciar aos homens e mulheres uma alfabetização científica na perspectiva da inclusão social. Há uma continuada necessidade de fazermos com que a ciência possa ser não apenas medianamente entendida por todos, mas, e principalmente, facilitadora do estar fazendo parte do mundo.

Sei o quanto estou laborando em (quase) utopias. Mas é por crer que essas mesmas utopias possam se transmutar na realidade de fazermos educação. Diria mais, é quase apenas por isso. Mas agora deixemos um pouco os sonhos. Há de se tentar convertê-los em realidades.

Trago, assim, a proposta teórica para adensar uma discussão. Essas são as minhas expectativas para a frutificação do binômio escrita - leitura. Sei também que posso estar sendo acusado de dicotômico, ao ape-

${ }^{3}$ Restringi a descrição ao mundo visível em oposição ao mundo sobrenatural e também àquilo que se poderia chamar de mundo intelectual (estudado pelas ciências humanas). A limitação de mundo visível não é suficientemente adequada, pois os estudos das ciências naturais incluem descrições no nível do mundo molecular, atômico, subatômico e mesmo das radiações que são invisíveis; logo, não estariam incluídos no assim chamado mundo visível. Talvez uma melhor caracterização seria referir ao mundo material, em oposição ao mundo sobrenatural e ao mundo intelectual. 
lar para essa relação binomial. Aceito que não há uma separação nítida entre aquele que é o autor e aquele que é o leitor. Um e outro, nesse processo, interconvertem papéis. O leitor também passa a ser autor, refazendo com sua leitura um novo texto. Mesmo que refaça caminhadas, buscando outros embasamentos, tenho em outros livros dois capítulos ${ }^{4,5}$ acerca do tema, que (des)constroem essa discussão.

Para fazer uma oposição ao presenteísmo (vinculação exclusiva ao presente, sem enraizamento com o passado e sem perspectivas para o futuro) e ao cientificismo (crença exagerada no poder da ciência e/ ou atribuição à mesma de fazeres apenas benéficos), ${ }^{6}$ ainda tão marcadamente presentes nos dias atuais, especialmente em nossas salas de aula, inclusive nas universidades, insisto na necessidade de considerar que essa linguagem é um constructo humano, portanto, mutável e falível (Chassot, 1995, p. 198). Sempre parece oportuno ter presente as afirmações de Granger:

A ciência é uma das mais extraordinárias criações do homem, que lhe confere, ao mesmo tempo, poderes e satisfação intelectual, até pela estética que suas explicações lhe proporcionam. No entanto, ela não é lugar de certezas absolutas e [...] nossos conhecimentos científicos são necessariamente parciais e relativos. $(1994, \text { p. } 113)^{7}$

É para essa concepção de ciência - um dos mais extraordinários feitos humanos, mas não-lugar de certezas - que trago interrogações para ampliar a possi-

${ }^{4}$ Chassot (1993, p. 71-89): o Capítulo 5 - Do esoterismo ao exoterismo, apresenta uma análise do hermetismo da linguagem corrente no ensino (de química), usando alguns pressupostos de um respeitado teórico da educação: Bernstein.

${ }^{5}$ Chassot (2000, p. 111-131): Capítulo 5 - Linguagem (química) e poder na sala de aula, instrumentos para uma construção mais crítica no fazer Educação.

${ }^{6}$ Acerca de presenteísmo e cientificismo, ver Chassot (1998a, 1998b, 2000).

${ }^{7}$ A transcrição da primeira frase está ligeiramente modificada, sem alteração do sentido, pois parece haver um erro gramatical (provavelmente de tradução) na edição brasileira. bilidade de pensarmos a ciência como uma linguagem para entendermos o mundo natural. Por isso, quando discuto alfabetização científica, insisto na necessidade de considerá-la como "o conjunto de conhecimentos que facilitariam aos homens e mulheres fazer uma leitura do mundo onde vivem" (Chassot, 2000, p. 19). Assim, concordo com Woolgar (1991), que, ao tentar abrir aquela caixa preta em que os cientistas - com sua linguagem hermética e esotérica converteram a ciência, mostra que ela não descobre o mundo, mas o quanto é o mundo que a descobre. O mundo é (existe) independente da ciência. Esta o torna inteligível, e a tecnologia, como aplicação da ciência, modifica esse mundo. Por exemplo, a produção de energia elétrica a partir de uma queda d'água ou do aproveitamento de ventos é o resultado de uma aplicação de conhecimento acerca da natureza do mundo natural. Isso transforma o mundo natural mas não altera a sua essencialidade, por exemplo, em termos do princípio da conservação da energia.

Amplio mais a importância ou as exigências de uma alfabetização científica. Assim como se exige que os alfabetizados em língua materna sejam cidadãs e cidadãos críticos, em oposição, por exemplo, àqueles que Bertolt Brecht ${ }^{8}$ classifica como analfabetos políticos, seria desejável que os alfabetizados cientificamente não apenas tivessem facilitada a leitura do mundo em que vivem, mas entendessem as necessidades de transformá-lo - e, preferencialmente, transformá-lo em algo melhor. Tenho sido recorrente na defesa da exigência de com a ciência melhorarmos a vida no planeta, e não torná-la mais perigosa, como ocorre, às vezes, com maus usos de algumas tecnologias.

Parece que merece ser questionado, liminarmente, se essa alfabetização científica é algo próprio, ou melhor, é de interesse apenas daqueles que estão diretamente ligados à ciência. Usualmente, conhecer a ciência é assunto quase vedado àqueles que não pertencem a essa esotérica comunidade científica. Já discuti em

\footnotetext{
${ }^{8}$ Site da International Brecht Society: http://polyglot.Iss.wisc.edu/
} german/brecht/ 
diversos textos o quanto há necessidade de nós, professoras e professores de disciplinas escolares, especialmente aquelas da área de ciências, fazermos a migração do esoterismo para o exoterismo ${ }^{9}$ (Chassot, 1993, p. 71; 1995, p. 161). Assim, a primeira explicação para a exclusão que decretamos a muitos é fazermos do nosso instrumental de leitura da natureza algo hermético ou esotérico. Thuillier (1990, p. 87), ao exemplificar o quanto se consegue ser hermético na linguagem da ciência, apresenta esotéricas (e desnecessárias) definições do número um quase incompreensíveis para os mais expertos algebristas.

Não desconheço, aqui, as razões históricas, muitas vezes até de segurança, que fizeram a ciência usar uma linguagem asséptica e hermética. Nunca desconsidero, como professor de química, minha ancestralidade nos alquimistas medievos. Discuto isso mais extensamente em diferentes capítulos de $E d u$ cação conSciência (Chassot, no prelo), quando falo de desafios curriculares para fazer possível um outro mundo e também quando discuto a alfabetização científica fazendo inclusão social. Relato, por exemplo, o trabalho com sementes que não são sementes ${ }^{10} \mathrm{em}$ um curso de pedagogia.

Retomo a problematizção da concepção da ciência como uma linguagem. Proponho fazermos juntos alguns adensamentos teóricos nessa dimensão. Tomo como referência a aula inaugural da cadeira de Semiologia ${ }^{11}$

${ }^{9}$ As referências às expressões exoterismo e esoterismo usadas aqui não têm correspondência com aquelas usadas pelo epistemólogo Luwidg Fleck.

${ }^{10} \mathrm{Um}$ dos trabalhos que tenho realizado na disciplina de Metodologia de Ensino de Ciências está relacionado com sementes caipiras versus biopirataria. Material disponível no site: www.humanas.unisinos.br/pastanet

${ }^{11}$ Ciência geral dos signos, segundo Ferdinand de Saussure, que estuda todos os fenômenos culturais como se fossem sistemas de signos, isto é, sistemas de significação. Em oposição à lingüística, que se restringe ao estudo dos signos lingüísticos, ou seja, da linguagem, a semiologia tem por objeto qualquer sistema de signos (imagens, gestos, vestuários, ritos etc.); semiótica. É Barthes
Literária no Collège de France ${ }^{12}$ pronunciada por Roland Barthes no dia 7 de janeiro de 1977. Sem enveredar na área da semiótica, busco em Barthes (1996) ${ }^{13}$ uma ratificação, quando ele afirma, categórico: "O objeto em que se inscreve o poder, desde toda a história humana, é: a linguagem - ou, para ser mais preciso, sua expressão obrigatória: a língua"

(1996) que, na aula antes referida, diz que "a semiologia, que se pode definir canonicamente como a ciência dos signos, saiu da lingüística. [...] É esta desconstrução da lingüística que chamo, quanto a mim, de semiologia" (p. 30).

${ }^{12} \mathrm{O}$ Collège de France - $\mathrm{CdF}$ - é um estabelecimento de ensino criado em 1540 pelo rei Francisco I, fora da universidade. Chamado sucessivamente de Colégio do Rei, Colégio das Três Línguas, Colégio Real, Colégio Nacional (durante a Revolução), Colégio Imperial (com Napoleão) e finalmente Colégio de França (com a Restauração). Aberto a todos, gratuitamente, os cursos são ministrados pelos mais eminentes professores e conta com cerca de 50 cadeiras relativas a todas as disciplinas. Os títulos das cadeiras são fontes de referência de domínios muito amplos do conhecimento: matemática, física, química, biologia, história, arqueologia, lingüística, orientalismo, filosofia, ciências sociais. Duas cadeiras são reservadas a sábios estrangeiros que são convidados pelo Collège a oferecer cursos, em geral por um período de um a dois meses. As cadeiras não são permanentes. Assim, o CdF tem uma liberdade considerável nas suas atividades de ensino e de pesquisa, podendo adaptar-se aos progressos realizados nos diferentes domínios do conhecimento. Os cursos são abertos a todos, sem inscrições prévias. Cada ano, cerca de cinco mil ouvintes seguem os diferentes cursos. Diferentemente, os laboratórios e centros de pesquisa são reservados aos pesquisadores. Hoje o CdF é considerado referência internacional na construção do conhecimento.

${ }^{13}$ A edição de A aula (Barthes, 1996) vem acompanhada de excelente posfácio (p. 49-89) de Leyla Perrone-Moisés, ex-aluna de Barthes, que foi quem traduziu o texto para a edição brasileira que uso neste texto. A tradutora, ao analisar o conteúdo e as implicações da obra, faz observações acuradas sobre ela. O "Caderno Mais" da Folha de São Paulo de 17 de novembro de 2002 traz como matéria de capa um dossiê sobre Barthes que inclui um alentado texto de Leyla Perrone-Moisés. 
(p. 12). Uma leitura (da história) ${ }^{14}$ da ciência quase que poderia ser feita com essas mesmas palavras. Encontramos, nas sucessivas disputas de poder na história da construção do conhecimento científico, isso que Barthes diz sobre a língua.

A aula prossegue afirmando:

A linguagem é uma legislação, a língua é seu código. Não vemos o poder que reside na língua, porque esquecemos que toda língua é uma classificação, e que toda classificação é opressiva: ordo quer dizer, ao mesmo tempo, repartição e cominação. (p. 12)

Barthes falava, então, da língua francesa, e mostrava, por exemplo, as dificuldades impostas pelas exigências de ter que escolher sempre entre o masculino e o feminino, enquanto o neutro é proibido. Eu o vejo falando da ciência, ou melhor da linguagem científica, que com seus códigos se faz língua, quando ele diz:

Assim, por sua própria estrutura, a língua implica em uma relação fatal de alienação. Falar, e com maior razão discorrer, não é comunicar, como se repete com demasiada frequiência, é sujeitar. Toda a língua é uma reição generalizada. (p. 13)

Mesmo quando A aula assume um tom aparentemente mais radical, é possível fazer associações com a ciência quando Barthes diz: "a língua, como desempenho de toda a linguagem, não é nem reacionária, nem progressista; ela é simplesmente fascista; pois o fascismo não é impedir de dizer, é obrigar a dizer" (p. 14). Trago, como ratificação à minha adesão barthesiana, Paul Feyerabend (1924-1994), autor de

${ }^{14}$ Tenho na história da ciência uma referência muito especial para facilitação das discussões acerca da alfabetização científica.

${ }^{15}$ Cominação, ato de cominar: Ameaçar com pena ou castigo no caso de infração ou falta de cumprimento de contrato ou de preceito, ordem, mandato etc. (a nota é minha). obras que foram decisivas para novas concepções de ciência, como seu discutidíssimo livro Contra o método. Ele destaca que "a distinção entre Ciência e mito não é tão evidente" (Le Monde, 1989, p. 26). Então, mais uma vez, me parece claro por que Feyerabend, um dos críticos mais perspicazes, faz análises da ciência tão desestabilizadoras. Não é sem razão que ele é chamado em rodas mais fechadas de "terrorista epistemológico", tendo sido chamado por alguns físicos, mais recentemente, de "o pior inimigo da ciência", encabeçando uma lista em que são nomeados Karl Popper, Imre Lakatos e Thomas Kuhn (Regner, 1996). Prefiro estar ao lado de Feyerabend, e não de seus críticos conservadores.

Quando se busca entender o porquê da contestação que cientistas, especialmente os (auto)denominados hard, fazem, por exemplo, àqueles que buscam uma leitura da ciência em dimensões menos positivistas, podemos entender o que Barthes diz da linguagem e ver também a ciência, ou seus autores canônicos ou mais ortodoxos, exercendo dominação: obrigando a dizer ou a fazer.

Há duas dimensões que demandam estudos e investigações: a primeira, o quanto o conhecimento científico é uma instância privilegiada de relações de poder e esse conhecimento, como patrimônio mais amplo da humanidade, deve ser socializado; a segunda, o quanto há cada vez mais exigências de que migremos do esoterismo ao exoterismo, para que se ampliem as possibilidades de acesso à ciência. Uma e outra dessas dimensões mereceram textos que já referi aqui.

Outra vez trago Barthes falando da língua, considerando - para os propósitos deste texto - como se sua aula fosse acerca dos códigos da ciência:

[...] a língua entra a serviço de um poder. Nela, infalivelmente, duas rubricas se delineiam: a autoridade da asserção, o gregarismo da repetição. Por um lado, a língua é imediatamente assertiva: a negação, a dúvida, a possibilidade, a suspensão de julgamento requerem operadores particulares que são eles próprios retomados num jogo de máscaras linguageiras. [...] Por outro lado, os signos de que a língua é feita, os signos só existem na medida em que são reco- 
nhecidos, isto é, na medida em que se repetem; o signo é seguidor, gregário; em cada signo dorme este monstro: nunca posso falar senão recolhendo aquilo que se arrasta na língua. [...] Na língua, portanto a servidão e o poder se confundem inelutavelmente (1996, p. 15).

Pode-se ver, na releitura que faço de A aula, usando-a para a ciência, que há uma tentativa de rebeldia barthesiana contra os códigos da ciência, assim como ele desentranhou a semiologia da lingüística (p. 30). Todavia, não adiro ao quase consenso de que nossos textos devam parecer herméticos e escritos apenas para uma auto-satisfação acadêmica. Há situações em que parece ser possível dizer de alguns de nossos textos acadêmicos aquilo que se diz de algumas obras de arte: um outro artista não a identifica como arte; um outro cientista, da mesma área, não entende o texto. Nunca é demais recordar o aprendizado que as ciências humanas tiveram com o caso Sokal. ${ }^{16}$ Há, com a ciência que se faz, um compromisso ético de ajudar aos homens e às mulheres na solução de importantes problemas (Del Percio, 2000). Ao referir a necessidade de ajuda, parece evidente que não esteja propondo aqui uma postura messiânica da Academia. A ciência, todavia, tem compromissos com a sociedade, pois é a sociedade a cofinanciadora das pesquisa que se fazem na ciência.

Defendo o quanto há necessidade de nós, professoras e professores de disciplinas científicas, fazermos a migração do esoterismo para o exoterismo. Há aqui uma outra direção que pode iluminar nossas pesquisas: como fazer do saber acadêmico um saber escolar. Tenho me envolvido também em como fazer do saber popular um saber escolar. Essa é uma discussão que ainda não está suficientemente presente na Academia.

Há nessa dimensão a busca de se investigar um ensino mais impregnado com posturas mais holísticas - isto é, com um ensino de ciências que contemple aspectos históricos, dimensões ambientais, pos-

${ }^{16}$ Escrevi A farsa ou embuste Sokal (Chassot, 2000, p. 403420) como um exemplo do quanto as vaidades e querelas também se fazem presentes na academia. turas éticas e políticas, mergulhadas na procura de saberes populares e nas dimensões das etnociências -, proposta que traz vantagens para uma alfabetização científica mais significativa, como também confere dimensões privilegiadas para a formação de professoras e professores.

Mesmo que também reconheçamos no desempenho da ciência posturas que nem sempre são progressistas, ou que até são nitidamente reacionárias, e muitas vezes, simplesmente fascistas no seu não impedir de dizer, mas obrigar a dizer, usando as referências de Barthes à língua e à linguagem, é preciso reconhecer que esse constructo que denominamos ciência é decisivo, ainda que não definitivo. Logo, a ele não devemos nos submeter. Precisamos saber usálo. Isso me parece ser um indicador para uma alfabetização científica.

Assim, poderíamos pensar que alfabetização científica signifique possibilidades de que a grande maioria da população disponha de conhecimentos científicos e tecnológicos necessários para se desenvolver na vida diária, ajudar a resolver os problemas e as necessidades de saúde e sobrevivência básica, tomar consciência das complexas relações entre ciência e sociedade (Furió et al., 2001). Parece válido considerar a ciência como uma parte da cultura de nosso tempo (Serres, 1991).

Isso não significa uma adesão exclusiva à ciência imposta pela Europa, a partir do século XV. Há, assim, uma continuada necessidade de revermos marcos que usualmente definem o início da chamada ciência moderna. Por exemplo, eu fui simplista e reducionista em A Ciência através dos tempos (Chassot, 1994), quando refiro a revolução galilaica e a copernicana e encimo um capítulo com um título no mínimo tendencioso: Século 16: nasce a ciência moderna, numa leitura que desconhece o que se fez no mundo não-europeu. Reabilito-me, um pouco, em outros textos (Chassot, 1999, e particularmente Chassot, 2001).

Vale recordar que há 100 anos o químico francês Marcelin Berthelot (1827-1907), um dos primeiros grandes especialistas em síntese orgânica, com investigações que alçaram a termoquímica a uma especia- 
lização muito importante, exageradamente profetizava, como senador da República e presidente da Academia de Ciências:

A Ciência possui doravante a única força moral que pode fundamentar a dignidade da personalidade humana e constituir as sociedades futuras. A Ciência domina tudo: só ela presta serviços definitivos. [...] $\mathrm{Na}$ verdade, tudo tem origem no conhecimento da verdade e dos métodos científicos pelos quais ele é adquirido e propagado: a política, a arte, a vida moral dos homens, assim como sua indústria e sua vida prática. (apud Chrétien, 1994, p. 26)

Vivia-se o auge de descobertas significativas, e que, então, pareciam definitivas. Mesmo que possa parecer não crível, é preciso acentuar que não devemos pensar a ciência como pronta, acabada, completamente despojada, como uma nova e dogmática religião, com o "deus saber" imperando no novo milênio. A marca da ciência de nossos dias é a incerteza. É importante recordar Ilya Prigogine (1917- ), Prêmio Nobel de Química de 1977, em uma afirmação categórica: "Só tenho uma certeza: as de minhas muitas incertezas" (Le Monde, 1989, p. 59). Assim, é preciso que vejamos nessas incertezas a marca da pós-modernidade; uma realidade, e não um estigma. Antigamente a ciência nos falava de leis eternas. Hoje, nos fala da história do universo ou da matéria e nos propõe sempre novos desafios que precisam ser investigados. Este é o universo das probabilidades, e não das certezas.

Ao referir as nossas não-certezas, vale destacar o quanto o dogmatismo é uma marca muito presente em nossas salas de aula. Pode-se creditá-lo às origens da universidade e da escola. É preciso recordar que a universidade (no mundo ocidental) e também as escolas têm suas origens na Igreja e a ela permaneceram simbioticamente ligadas durante séculos. Assim a escola - como sempre ocorreu com a Igreja - parecia ser o locus da verdade. Vale lembrar um exemplo histórico de contestação: Paracelso (1493-1541) sabia o segredo das minas, da medicina popular, da alquimia e da ciência dos clássicos, mas rejeitava o que era estabelecido como verdade. Rebelou-se contra a autorida- de eclesiástica e contra o dogmatismo presente na universidade. Como conseqüência, foi considerado um pária na academia.

Nas aulas, em qualquer etapa da escolarização, poucas vezes falamos em modelos prováveis, mesmo que a maioria de nossas discussões nas ciências se desenvolvam através de modelos. Nunca é demais insistir que os modelos que usamos não são a realidade. São aproximações facilitadoras para entendermos a realidade e que nos permitem algumas (limitadas) generalizações. Talvez a marca da incerteza, hoje tão mais presente na ciência, devesse estar mais fortemente presente em nossas aulas. Retifiquemos as certezas de Berthelot: a ciência não tem a verdade, mas tem algumas verdades transitórias.

Aliás, na educação brasileira, principalmente aquela do início do século XX, ao lado da influência do dogmatismo que herdamos pelas origens da escola e da universidade, temos que acrescentar o positivismo comtiano. O livro Cours de philosophie positive ${ }^{17}$ foi certamente a obra mais lida pela elite intelectual brasi-

${ }^{17}$ Comte, na sua primeira lição do Curso de filosofia positi$v a$ (Comte, 1973, p. 9-11), ensina que cada uma de nossas concepções principais, cada ramo de nossos conhecimentos, passa sucessivamente por três estados históricos diferentes: o estado teológico, onde o espírito investiga a natureza íntima dos seres; o estado metafísico, uma modificação geral do primeiro, onde os agentes sobrenaturais são substituídos por forças abstratas, concebidas como capazes de engendrar elas próprias todos os fenômenos observados, cuja explicação consiste em determinar para cada um uma entidade correspondente; e enfim, o estado positivo, onde o espírito humano, reconhecendo a impossibilidade de obter noções absolutas, renuncia a procurar a origem e o destino do universo, a conhecer as causas íntimas dos fenômenos, para preocupar-se unicamente em descobrir, graças ao uso bem combinado do raciocínio e das observações, suas leis efetivas, a saber, suas relações invariáveis de sucessão e similitude. A explicação dos fatos, reduzida então a seus termos reais, se resume de agora em diante à ligação estabelecida entre os diversos fenômenos particulares e alguns fatos gerais, cujo número o progresso da ciência tende cada vez mais a diminuir. 
leira, e nesta se incluem os militares que fizeram a República. O positivismo comtiano, mesmo com características de um sistema filosófico fechado e inspirado em resultados científicos, teve no Brasil uma significativa influência nas escolas militares e foi legado durante a República para as escolas de engenharia, e delas para os níveis anteriores à universidade. A ideologia positivista comtiana funcionou como um inibidor para a expansão do conhecimento, pois, entre outras afirmações, Comte dizia que "a ciência estava pronta, acabada, pois seus fundamentos estavam consolidados". E ainda: "Ciência, logo previsão, logo ação." O positivismo garante a justificação do poder técnico e, mais que isso, do poder dos tecnocratas.

A força das idéias comtianas sobre a ciência pode ser vista nas suas idéias sobre a evolução. Tendo falecido dois anos antes da publicação, em 1857, da Origem das espécies, de Darwin, Comte não aceitava a teoria da evolução por julgá-la contrária aos fatos que conhecia e, por isso assim escreveu, no Curso de filosofia positiva (1973, p. 301): "Mas a fixidez essencial das espécies garante-nos que essa série [a grande série biológica] será sempre composta de termos nitidamente distintos, separados por intervalos intransponíveis". Acredito que essa frase serve como um bom exemplo do chamado positivismo comtiano.

Superar essas marcas de um jeito muito continuado de pensar é uma tarefa nem sempre fácil. A superação do dogmatismo parece ser uma das necessidades do ensino das ciências.

\section{À guisa de epílogo}

Como fazer uma alfabetização científica? Parece que se fará uma alfabetização científica quando o ensino da ciência, em qualquer nível - e, ousadamente, incluo o ensino superior, e ainda, não sem parecer audacioso, a pós-graduação -, contribuir para a compreensão de conhecimentos, procedimentos e valores que permitam aos estudantes tomar decisões e perceber tanto as muitas utilidades da ciência e suas aplicações na melhora da qualidade de vida, quanto as limitações e consequiências negativas de seu desenvolvimento.
Vale observamos que não podemos ver na ciência apenas a fada benfazeja que nos proporciona conforto no vestir e na habitação, nos enseja remédios mais baratos e mais eficazes, ou alimentos mais saborosos e mais nutritivos, ou ainda facilita nossas comunicações. Ela pode ser - ou é - também uma bruxa malvada que programa grãos ou animais que são fontes alimentares da humanidade para se tornarem estéreis a uma segunda reprodução. Essas duas figuras (a fada e a bruxa) muito provavelmente aparecerão quando ensinamos ciências (Chassot, 2000).

Acredito que tenha ampliado a possibilidade de respostas a questões como: O que é, por que e como fazer a alfabetização científica? Sei que cada uma das muitas respostas a essas interrogações poderão ser ainda muito ampliadas. Agora fica, ainda, uma pergunta mais crucial: Para que(m) é útil a alfabetização científica que fazemos?

ATTICO CHASSOT, licenciado em química e doutor em educação pela Universidade Federal do Rio Grande do Sul (UFRGS), é professor do Programa de Pós-Graduação em Educação na Universidade do Vale do Rio dos Sinos (UNISINOS), no Rio Grande do Sul. Trabalha na linha de pesquisa Currículo, cultura e sociedade, pesquisando a temática: Currículo, história da ciência e alfabetização científica. Entre suas publicações destacam-se: A ciência através dos tempos (Moderna, 2002) e Alfabetização científica: questões e desafios para a educação (Editora Unijuí, 2001). E-mail: achassot@portoweb.com.br

\section{Referências bibliográficas}

ABREU, Rozana Gomes de, (2002). A integração curricular na área de ciências da natureza, matemática e suas tecnologias nos Parâmetros Curriculares Nacionais para o Ensino Médio. Dissertação de mestrado. Programa de Pós-Graduação em Educação da Universidade Federal do Rio de Janeiro.

AGUILAR, T., (1999). Alfabetización científica para la ciudadanía. Madrid: Narcea.

BARTHES, Roland, (1996). A aula. $7^{\mathrm{a}}$ ed. São Paulo: Cultrix.

CHALMERS, Alan, (1994). A fabricação da ciência. São Paulo: Editora da UNESP. 
CHASSOT, Attico, (1993). Catalisando transformações na educação. Ijuí: Editora Unijuí.

, (1994). A ciência através dos tempos. São Paulo: Moderna.

, (1995). Para que(m) é útil o ensino? Canoas: Editora da Ulbra.

, (1998a). Fazendo uma oposição ao presenteísmo com o ensino da filosofia da ciência e da história da ciência. Episteme, v. 3, no 7, p. 97-107.

, (1998b). Presenteismo: uma conspiração contra o passado que ameaça o futuro. Espaço da Escola, ano 4, nº 28, p. 13-19.

(1999). Buscando um eixo histórico para o ensino das ciências da terra. In: CAMPOS, Heraldo, CHASSOT, Attico, (orgs.). Ciência da terra e meio ambiente: diálogo para (inter)ações no planeta. São Leopoldo: Editora Unisinos. , (2000). Alfabetização científica: questões e desafios para a educação. Ijuí: Editora Unijuí.

, (2001). Outro marco zero para uma história da ciência latino-americana. Química Nova na Escola, ano 7, p. 42-45. , (2003). (inédito). Educação conSciência.

CHRÉTIEN, Claude, (1994). A ciência em ação. São Paulo: Papirus.

COMTE, Auguste, (1973). Curso de filosofia positiva. São Paulo: Abril (Coleção Os Pensadores).

DEL PERCIO, Enrique M., (2000). Tiempos modernos: una teoria de la dominación. Buenos Aires: Altamira.

FURIÓ, C., VILVHES, A., GUISASOLA, J., ROMO, V., (2001). Finalidades de la enseñanza de las ciencias en la secundaria obligatoria. ¿Alfabetización científica o propedéutica? Enseñanza de las ciencias, v. 19, n 3, p. 365-376.
FOUREZ, Gerard, (1995). A construção das ciências. Introdução à filosofia e à ética das ciências. São Paulo: Editora da UNESP.

GRANGER, Gilles-Gaston, (1994). A ciência e as ciências. São Paulo: Editora da UNESP.

JAPIASSU, H., MARCONDES, D., (1990). Dicionário básico de filosofia. Rio de Janeiro: Jorge Zahar Editor.

LE MONDE, (1989). Idéias contemporâneas (entrevistas diversas). São Paulo: Ática.

LOPES, Alice Ribeiro Casimiro, (1999). Conhecimento escolar: ciência e codidiano. Rio de Janeiro: Editora da UERJ.

MINISTÉRIO DA EDUCAÇÃO (MEC), SECRETARIA DE EDUCAÇÃO MÉDIA E TECNOLÓGICA (SEMTEC), (1999). Parâmetros curriculares nacionais para o Ensino Médio. Brasília: MEC/SEMTEC (versão disponível no site do MEC).

PUIGCERVER, Manuel; SANS, Maria Cristina, (2002). Vacas locas, enseñanza: aprendizaje y alfabetización científica. Alambique -Didáctica de las ciencias experimentales, $\mathrm{n}^{\circ} 32$, p. 24-31.

REGNER, Anna Carolina Krebs Pereira, (1996). Feyerabend e o pluralismo metodológico. Episteme, v. 1, nº 2, p. 61-78.

SERRES, Michel, (1991). Historia de las ciencias. Madrid: Cátedra.

THUILLIER, Pierre, (1990). El saber ventrílocuo: como habla la cultura a través de la ciencia. México: Fondo de Cultura Económica.

WOOLGAR, Steve, (1991). Ciencia: abriendo la caja negra. Barcelona: Anthropos. 